Review began 10/28/2021 Review ended 11/11/2021 Published 11/16/2021

() Copyright 2021

Perez-Malagon et al. This is an open access article distributed under the terms of the Creative Commons Attribution License CC-BY 4.0., which permits unrestricted use, distribution, and reproduction in any medium, provided the original author and source are credited.

\section{Lack of Medical Criteria for Long-Term Oxygen Therapy Usage According to International Guidance in Outpatients With Chronic Hypoxemia}

Carlos David Perez-Malagon ${ }^{1,2}$, Raul Barrera ${ }^{3}$

1. Centro de Ciencias Biomedicas, Universidad Autónoma de Aguascalientes, Aguascalientes, MEX 2. Clinical Service Rotation, Unidades Médicas de Atención Ambulatoria, Instituto Mexicano del Seguro Social, Aguascalientes, MEX 3. Autoimmunity, National Institute of Respiratory Diseases, Mexico City, MEX

Corresponding author: Raul Barrera, biologiamoleculardelacelula1@gmail.com

\section{Abstract \\ Background}

Benefits of long-term oxygen therapy (LTOT) have been observed in hypoxemic respiratory patients. Reports have shown the lack of observance among healthcare professionals of LTOT. Thus, this study aimed to determine the demographic characteristics and observance of the medical indication of LTOT according to the international guidelines.

\section{Methodology}

A cross-sectional study was conducted on patients who attended the Medical Unit in Aguascalientes, Mexico to re-evaluate the need for LTOT. Data are presented as mean \pm standard deviation. Statistical analyses were performed using the chi-square test or unpaired t-tests. P-values of $<0.05$ were considered statistically significant.

\section{Results}

From 813 outpatients attended to re-evaluate whether they met the medical criteria to use LTOT, 93 outpatients were excluded, and the remaining 714 outpatients were enrolled. The mean age of the patients was $70.0 \pm 15.1$ years, with a female gender predominance $(59.1 \%)$. The mean $\mathrm{PaO}_{2}$ level in room air was 7.9 $\pm 2.3 \mathrm{kPa}$. Hemoglobin and hematocrit levels were $14.9 \pm 4.1 \mathrm{~g} / \mathrm{dL}$ and $44.7 \pm 8.4 \%$, respectively. The mean levels of $\mathrm{PaO}_{2}$ were higher in female patients $(8.1 \pm 2.5 \mathrm{kPa}$ vs. $7.6 \pm 1.9 \mathrm{kPa} ; \mathrm{p}=0.01)$. The most common diagnosis was chronic obstructive pulmonary disorder (60.5\%). Moreover, the specialty that most indicated the use of LTOT was pulmonology (57.8\%); however, $36.8 \%$ of patients who used LTOT did not have any criteria according to international guidelines.

\section{Conclusions}

Although a significant percentage of patients do not use LTOT correctly, the most important finding is that the medical indication of LTOT by physicians is not always correct, leading to an excessive prescription of oxygen.

Categories: Pulmonology

Keywords: survey, respiratory failure, chronic obstructive pulmonary disease, hypoxemia, hypoxemic, long-term oxygen therapy

\section{Introduction}

Hypoxemia is a state in which oxygen is not available in sufficient quantity in the blood to maintain adequate homeostasis in different organs, leading to a poor prognosis with high mortality; therefore, it must be treated with oxygen therapy [1]. Long-term oxygen therapy (LTOT) refers to the continuous administration of oxygen in patients with chronic hypoxemia to maintain adequate oxygen saturation [2].

Two randomized controlled trials, namely, the Nocturnal Oxygen Therapy Trial (NOTT) and the British Medical Research Council (MRC) trial, conducted in the late 1970s demonstrated that LTOT should be used for patients with chronic obstructive pulmonary disorder (COPD) if their resting awake oxygen tension in arterial blood $\left(\mathrm{PaO}_{2}\right)$ is $<7.3 \mathrm{kPa}(\leqslant 55 \mathrm{mmHg})$, arterial oxygen saturation $\left(\mathrm{SaO}_{2}\right)$ is $\leqslant 88 \%, \mathrm{PaO}_{2}$ is in the range of $7.3-7.9 \mathrm{kPa}\left(56-59 \mathrm{mmHg}\right.$ ), or if $\mathrm{SaO}_{2}$ is $89 \%$. Moreover, LTOT should be administered in the presence of signs of cor pulmonale and at a hematocrit level of $>55 \%[3,4]$. LTOT has also been extended to COPD patients with resting $\mathrm{PaO}_{2}$ of $<7.9 \mathrm{kPa}(<60 \mathrm{mmHg})$ and decreased $\mathrm{SaO}_{2}$ during exercise or sleep [5]. Both the 
NOTT and MRC trials reported the following indications for LTOT administration: $\mathrm{SaO}_{2}$ of $<88 \%$ during sleep or a lowering of $\mathrm{PaO}_{2}$ to $1.3 \mathrm{kPa}(10 \mathrm{mmHg})$ or more, a fall in $\mathrm{SaO}_{2}$ of more than $5 \%$ with signs or symptoms suggestive of hypoxemia during exercise, lowering of $\mathrm{PaO}_{2}$ to $7.3 \mathrm{kPa}\left(55 \mathrm{mmHg}\right.$ ), or lowering of $\mathrm{SaO}_{2}$ to $88 \%$ [5]. Thus, the goal of LTOT in any of the above indications is to increase the baseline $\mathrm{PaO}_{2}$ to at least $>8.0$ $\mathrm{kPa}(56-59 \mathrm{mmHg})$ and/or $\mathrm{SaO}_{2}$ to $90 \%$ to preserve vital organ functions by ensuring adequate delivery of oxygen $[2,3]$.

The application of LTOT has shown improvement in survival of hypoxemic patients [6] and has been associated with a decrease in vascular pulmonary resistance, pulmonary arterial hypertension, and hematocrit, as well as a reduction in right heart pressure, reduction in minute ventilation, air trapping, and improvement in exercise endurance, thus alleviating post-exercise dyspnea. Nevertheless, clinical trials have not reported benefits from LTOT in the prognosis, rate of hospitalization, or health-related quality of life in COPD patients with mild-to-moderate hypoxemia [4].

The benefits of LTOT for all hypoxemic respiratory patients have been extrapolated from the evidence of its life-saving effects in COPD, and many countries have extended programs for domiciliary oxygen. For example, when nocturnal supplemental oxygen is administered, it improves oxygenation and limits cardiac arrhythmias, prevents high blood pressure, improves the quality of life, and decreases the number of hospital admissions [2-4]. Furthermore, it is generally accepted without much evidence that LTOT in clinical practice is warranted in other forms of chronic respiratory failure such as pulmonary fibrosis, kyphoscoliosis, and cystic fibrosis when arterial blood gas criteria are similar to those established for COPD patients [7].

During our daily medical assistance of patients with chronic respiratory failure, we noticed a lack of observance among medical specialists toward the prescription of LTOT according to international guidelines, a situation which appears to be frequently reported in patients to require LTOT [8]. Thus, we designed a cross-sectional study using survey questionnaires for patients to whom LTOT was previously indicated to determine demographic characteristics and different aspects of the medical indications for LTOT to highlight the lack of observance among medical specialists toward the prescription of LTOT according to international guidelines.

\section{Materials And Methods}

We interviewed 813 patients who underwent medical evaluation for eight months at the Outpatient Clinical Medical Unit of Therapy, Aguascalientes, Mexico, a public facility serving the population affiliated to the Mexican Institute of Social Security, to re-evaluate whether they met the medical criteria to continue LTOT.

The criteria of qualification for LTOT were in accordance with policies and procedures of the American Thoracic Society (ATS) [9]. The criteria for LTOT were verified by two pulmonary specialists by checking medical history, physical examination, chest X-ray, electrocardiogram, echocardiography (when necessary), arterial blood gas analysis on room air, hematocrit, and hemoglobin.

The prescription of LTOT was defined as appropriate if at-rest $\mathrm{PaO}_{2}$ was $\leqslant 7.3 \mathrm{kPa}$ ( $\leqslant 55 \mathrm{mmHg}$ ) or when $\mathrm{PaO}_{2}$ was 56-59 mmHg or $\mathrm{SaO}_{2}$ was $\geqslant 89 \%-90 \%$, combined with radiological or electrocardiographic signs of pulmonary hypertension and/or secondary polycythemia (hematocrit exceeding $55 \%$ ).

The patient selection criteria for the survey included patients who were prescribed LTOT, those suffering from chronic non-malignant lung diseases, and those referred to the Outpatient Clinical Medical Unit of Therapy for routine follow-up at least twice per year. Additionally, patients with adequate clinical records (arterial blood gas, oxygen administration, and smoking status) were considered eligible.

This study was approved by the Research Ethics Committee of Clinical Medical Unit of Therapy of the IMSS Aguascalientes, Mexico, and all participating patients provided written informed consent.

The results are presented as the arithmetic mean \pm standard deviation (SD) or median (interquartile range) and frequencies and percentages for qualitative variables. Comparison between groups was performed using an unpaired t-test for quantitative variables with normal distribution, Mann-Whitney U-rank test for quantitative variables without normal distribution, and the chi-square test was used to compare proportions. Results were considered statistically significant at a $p$-value of $<0.05$. The analyses were performed using Stata statistical software package, version 10.0 (StataCorp LP, College Station, TX, USA).

\section{Results}

Over eight months, 813 patients at the Outpatient Clinical Medical Unit of Therapy underwent a routine follow-up to re-evaluate whether they met the medical criteria to use LTOT and continue with oxygen prescription. Of these, 93 outpatients were excluded from the study because they were using supplementary oxygen due to an obstructive apnea syndrome diagnosis, and the remaining 714 outpatients were enrolled in 


\section{Cureus}

the study. Demographic and clinical characteristics of outpatients attended to in the follow-up clinic are shown in Table 1.

\begin{tabular}{|c|c|c|c|}
\hline & Overall, $\mathbf{N}=714$ & Male, $\mathrm{N}=292$ & Female, $\mathrm{N}=422$ \\
\hline & Mean \pm SD & Mean \pm SD & Mean \pm SD \\
\hline Patient age (years) & $70.0 \pm 15.1$ & $71.4 \pm 13.9$ & $68.9 \pm 15.9$ \\
\hline Time elapsed since diagnosis (years) & $7.0 \pm 8.8$ & $6.9 \pm 9.0$ & $7.1 \pm 8.8$ \\
\hline Time using LTOT (years) & $2.5 \pm 3.1$ & $2.3 \pm 2.6$ & $2.6 \pm 3.3$ \\
\hline LTOT prescription (hours/day) & $11 \pm 6.1$ & $11.2 \pm 6.7$ & $10.8 \pm 5.6$ \\
\hline Oxygen flow (L/minute) & $2.5 \pm 0.8$ & $2.5 \pm 0.7$ & $2.5 \pm 0.9$ \\
\hline $\mathrm{PaO}_{2}(\mathrm{kPa})$ & $7.9 \pm 2.3$ & $7.6 \pm 1.9$ & $8.1 \pm 2.5^{\star}$ \\
\hline $\mathrm{PaCO}_{2}(\mathrm{kPa})$ & $4.5 \pm 0.8$ & $4.6 \pm 0.8$ & $4.5 \pm 0.8$ \\
\hline Hemoglobin (g/dL) & $14.9 \pm 4.1$ & $15.0 \pm 2.6$ & $14.8 \pm 4.9$ \\
\hline Hematocrit (\%) & $44.7 \pm 8.4$ & $45.6 \pm 8.4$ & $44.0 \pm 8.4^{\star}$ \\
\hline
\end{tabular}

TABLE 1: Baseline and clinical characteristics of the study population.

Asterisks indicate differences of statistical significance $\left({ }^{*} p<0.05\right)$ within the groups determined by the t-test.

SD: standard deviation; LTOT: long-term oxygen therapy

The mean age of the study participants was $70.0 \pm 15.1$ years (range, 19-99 years), with a female gender predominance (422 patients, 59.1\%). The average time for LTOT use after therapeutic prescription by a physician was approximately $7.0 \pm 8.8$ years, while the average time of LTOT use was approximately $2.5 \pm 3.1$ years. The average daily duration of LTOT in the entire group was $11.1 \pm 6.1$ hours/day with an oxygen flow of $2.5 \pm 0.8 \mathrm{~L} /$ minute. The mean $\mathrm{PaO}_{2}$ level on room air was $7.9 \pm 2.3 \mathrm{kPa}(59.6 \pm 17.7 \mathrm{mmHg})$. Hemoglobin and hematocrit levels were $14.9 \pm 4.1 \mathrm{~g} / \mathrm{dL}$ and $44.7 \pm 8.4 \%$, respectively.

Female patients were younger than male patients $(\mathrm{p}=0.030)$. Furthermore, no statistically significant differences were noted for the time since diagnosis while using LTOT, daily duration of LTOT, or oxygen flow (Table 1). However, the mean levels of $\mathrm{PaO}_{2}$ were higher in female than male patients $(8.1 \pm 2.5 \mathrm{kPa}$ vs. $7.6 \pm$ $1.9 \mathrm{kPa} ; \mathrm{p}=0.01)$, whereas hematocrit, although almost normal, was slightly lower $(44.0 \pm 8.4 \%$ vs. $45.6 \pm$ $8.4 \% ; \mathrm{p}=0.0125)$.

In this survey, we found that the most common diagnosis was COPD (60.5\%), followed by other diagnoses, each with a prevalence of less than $10 \%$ (Table 2). 


\section{Cureus}

\begin{tabular}{|c|c|c|c|}
\hline & Overall, N (\%) & Male, N (\%) & Female, $\mathbf{N}(\%)$ \\
\hline COPD & $432(60.5)$ & $188(64.4)$ & $244(57.8)$ \\
\hline ILD & $60(8.4)$ & $25(8.6)$ & $35(8.3)$ \\
\hline OSA & $36(5.0)$ & $15(5.1)$ & $21(5.0)$ \\
\hline Heart failure & $29(4.1)$ & $12(4.1)$ & $17(4.0)$ \\
\hline Renal Insufficlency & $15(2.1)$ & $4(1.4)$ & $11(2.6)$ \\
\hline Lung cancer & $15(2.1)$ & $8(2.7)$ & $7(1.7)$ \\
\hline ILD + other & $5(0.7)$ & $1(0.3)$ & $4(0.9)$ \\
\hline Bronchiectasis & $1(0.1)$ & $0(0.0)$ & $1(0.2)$ \\
\hline Others & $121(16.9)$ & $39(13.4)$ & $82(19.4)$ \\
\hline
\end{tabular}

TABLE 2: The total number of patients according to the respiratory diagnosis.

COPD: chronic obstructive pulmonary disease; ILD: diffuse interstitial lung disease; OSA: obstructive sleep apnea; SD: standard deviation

For these patients, the medical specialty that most indicated LTOT administration was pulmonologists (57.8\%), followed by internists (20.3\%) and cardiologists $(9.2 \%)$, although other specialties also indicated LTOT (Table 3).

\begin{tabular}{|c|c|c|c|}
\hline & \multirow{2}{*}{ Prescription of LTOT, $n$ (\%) } & \multicolumn{2}{|c|}{ Criteria of LTOT } \\
\hline & & Yes, n (\%*) & Not, $\mathrm{n}\left(\%^{*}\right)$ \\
\hline Pulmonologist & $413(57.8)$ & $267(59.2)$ & $146(55.5)$ \\
\hline Internist & $145(20.3)$ & $84(18.6)$ & $61(23.2)$ \\
\hline Cardiologist & $66(9.2)$ & $41(9.1)$ & $25(9.5)$ \\
\hline Nephrologist & $8(1.1)$ & $4(0.9)$ & $4(1.5)$ \\
\hline Geriatrics & $7(1.0)$ & $5(1.1)$ & $2(0.8)$ \\
\hline Neurologist & $2(0.3)$ & $1(0.2)$ & $1(0.4)$ \\
\hline Ear nose throat & $1(0.1)$ & $1(0.2)$ & $0(0.0)$ \\
\hline Rheumatologist & $1(0.1)$ & $1(0.2)$ & $0(0.0)$ \\
\hline Surgeon & $1(0.1)$ & $1(0.2)$ & $0(0.0)$ \\
\hline Oncologist & $1(0.1)$ & $0(0.0)$ & $1(0.4)$ \\
\hline Unknown & $69(9.7)$ & $46(10.2)$ & $23(8.7)$ \\
\hline
\end{tabular}

TABLE 3: Specialists who prescribed LTOT to patients according to international criteria.

Asterisks indicate the percentage regarding the number of patients with criteria positive or negative for LTOT.

LTOT: long-term oxygen therapy

When we compared study variables between those who met the criteria for LTOT with those who did not, we observed that there was no difference in age, the time elapsed with chronic hypoxemia, the time using LTOT, and oxygen flow (Table 4). 


\section{Cureus}

\begin{tabular}{|c|c|c|}
\hline & \multicolumn{2}{|c|}{ Criteria for prescription of LTOT } \\
\hline & Positive ( $\mathrm{N}=451 ; 63.2 \%$ ) & Negative $(\mathrm{N}=263 ; 36.8 \%)$ \\
\hline & Mean \pm SD & Mean \pm SD \\
\hline Age (years) & $70.1 \pm 15$ & $69.7 \pm 15.4$ \\
\hline Time elapsed since diagnosis (years) & $7.4 \pm 8.6$ & $6.4 \pm 9.2$ \\
\hline Time using LTOT (years) & $2.6 \pm 3.0$ & $2.1 \pm 3.1$ \\
\hline LTOT prescription (hours/day) & $11.3 \pm 5.2$ & $10.4 \pm 7.3$ \\
\hline Oxygen flow (L/minute) & $2.5 \pm 0.8$ & $2.5 \pm 0.8$ \\
\hline $\mathrm{PaO}_{2}(\mathrm{kPa})$ & $7.0 \pm 1.67$ & $9.5 \pm 2.67^{\star}$ \\
\hline $\mathrm{PaCO}_{2}(\mathrm{kPa})$ & $4.7 \pm 0.89$ & $4.2 \pm 0.77^{*}$ \\
\hline Hemoglobin (g/dL) & $15.6 \pm 4.8$ & $13.6 \pm 2.2^{*}$ \\
\hline Hematocrit (\%) & $46.7 \pm 8.9$ & $41.1 \pm 6.2^{\star}$ \\
\hline
\end{tabular}

TABLE 4: Comparison between patients with chronic hypoxemia who qualified or did not qualify for the criteria recommended by LTOT guidelines.

Asterisks indicate the differences in statistical significance $\left({ }^{*} p<0.05\right)$ within the groups determined by the t-test.

LTOT: long-term oxygen therapy; SD: standard deviation

\section{Discussion}

The benefits of LTOT in patients with chronic hypoxemia have been demonstrated in numerous studies, with improved survival being the most crucial [10]. Other benefits of LTOT include improved quality of life, improved exercise capacity, improved intellectual function and mental status, reduced secondary polycythemia, and stabilized pulmonary artery pressure [11].

Our surveys results showed that the mean age of outpatients using LTOT was $70.0 \pm 15.1$ years (range, 19-99 years), with patients largely suffering from chronic hypoxemia. This wide range is due to the inclusion of young patients who require LTOT for different diseases such as bronchiectasis and congenital cardiovascular, renal, and other diseases. The mean age was similar to previous studies. For example, Nasilowski et al. [12] in Poland reported a study of 30 patients (77\% with COPD) with a mean age of $67 \pm 9$ years, whereas Neri et al. [13], in a multicenter observational study conducted in Italy (1,504 patients, $74 \%$ COPD), found a mean age of $71.6 \pm 10$ years. Similarly, Mesquita et al. [14], in a study made in Brazil with 39 patients with COPD and exertional dyspnea, reported a mean age of 69.0 years (62.0-77 years). In a study done in Denmark including 182 patients with LTOT (84.1\% with COPD), Ringbaek et al. [15] in a report of 246 COPD patients found that those who received continuous oxygen therapy were younger than those who received noncontinuous oxygen therapy (mean age: $68.4 \pm 8.7$ vs $71.6 \pm 7.4$ years, respectively). Subsequently, in 2014 , the same group evaluated the changes among 14,965 COPD patients treated with LTOT from 2001 to 2010 and reported that the mean age increased from $73.4 \pm 9.0$ years to $74.8 \pm 9.7$ years [16].

Our study showed that $60.5 \%$ of outpatients with an LTOT prescription were diagnosed with COPD, which is a slightly lower percentage than that reported in other studies. For example, in Denmark, Ringbaek et al. [17] found that $84 \%$ of all surveyed patients who used LTOT had COPD, and similar percentages were reported by Nasilowski et al. [14] in Poland (77\%), Katsenos et al. [18] in Greece (74.7\%), Chaney et al. [19] in the United States (75\%), and Neri et al. [13] in Italy (74\%), whereas Coleta et al. [20], in Brazil, reported that 67.8-81.6\% of all patients treated with LTOT had COPD. Interestingly, Rico-Mendez et al. [21] in a study done in Mexico with patients receiving home-based LTOT reported that only $44 \%$ had a diagnosis of COPD.

Female patients predominated in our study (59.1\%) and were younger than male patients (females: $68.9 \pm$ 15.9 years vs. male: $71.4 \pm 13.9$ years; $p=0.030$ ). In a seven-year prospective cohort study of 435 outpatients with COPD conducted in Brazil, Machado et al. [22] observed that females were significantly younger than males ( $62.9 \pm 6.5$ vs. $69.3 \pm 7.2$ years, respectively), highlighting that females with severe COPD using LTOT for more than three years were at a higher risk of death. Likewise, Ringbaek et al. [15] in 2002 reported female predominance depending on their use of oxygen (continuous $56.8 \%$ vs. 48.8 non-continuous oxygen usage), although they did not report differences in age in relation to gender. 
A significant number of our patients (69.2\%) received the prescription for oxygen use for an average of 11 hours/day. Much of the initial research for LTOT addressed the precision of the daily duration of LTOT after therapeutic prescription. In particular, the prescription of oxygen administration for at least 15 hours/day is recommended according to current guidelines for patients with chronic hypoxemia $\left(\mathrm{PaO}_{2} \leqslant 55 \mathrm{mmHg}\right)$ because this treatment was found to reduce overall mortality compared to no LTOT ( $33 \%$ vs. $55 \%$; $p<0.05)$ [23].

However, despite the generally recommended daily duration of oxygen usage to achieve its goals, there is a large range of mean time between different surveys. For example, Atiş et al. [24] found that Turkish patients used LTOT for $9.7 \pm 6.09$ hours/day, which is equivalent to the study reported by Katsenos et al. [18] $(9 \pm 6.8$ hours/day), whereas Mesquita et al. [14] reported that the mean daily hours of using LTOT was as low as $8.0 \pm$ 1.2 hours/day and Nasilowsky et al. [12] reported that all patients used LTOT for an average of $12.5 \pm 4.6$ hours/day. However, they reported that only $37 \%$ of patients followed the prescription properly (mean oxygen use: $17.4 \pm 2.6$ hours/day), and in patients who did not adhere to prescription, the mean duration was $9.6 \pm 2.7$ hours/day. In other studies, Neri et al. [13] found that $79 \%$ of their patients used LTOT for more than 15 hours/day, whereas Gauthier et al. [25] in Canada reported that 115 patients were exposed to LTOT for an average of 17.8 hours/day, reaching the suggested daily hours by international guidelines; nevertheless, $40 \%$ of patients did not use LTOT according to their medical prescription. Ringbaek et al. [17] found that $65 \%$ of patients used LTOT for more than 15 hours/day, and $29 \%$ of the study participants used oxygen for fewer than 15 hours/day. In a subsequent study, the same group reported that adherent patients used LTOT for $18.5 \pm 3.4$ hours/day, whereas in nonadherent patients the duration was $8.2 \pm 4.8$ hours/day [15]. These large differences might be due to the observance of physicians and sociocultural aspects of patients.

The most common dose of LTOT used by our outpatients was $2.5 \mathrm{~L} /$ minute, but doses higher than $3 \mathrm{~L} / \mathrm{minute}$ were also used in $15 \%$ of cases, compared to the $10 \%$ reported by Neri et al. [13]. Although the NOTT study recommended that COPD hypoxemic patients can be prescribed 1-2 L/minute of LTOT and less than $10 \%$ of cases might require $3 \mathrm{~L} /$ minute or more to achieve adequate oxygenation, Wijkstra et al. [7] stated that there are substantial differences among countries as to how clinicians should choose the flow rates patients should receive at rest, during sleep, and during exercise. Thus, Ringbaek et al. [17] found that most patients were prescribed a flow of $1 \mathrm{~L} /$ minute, and only $7 \%$ were prescribed more than $1.5 \mathrm{~L} /$ minute. Another study found that adherent and nonadherent LTOT patients used $1.3 \pm 0.6$ to $1.3 \pm 0.7 \mathrm{~L} /$ minute, a low dose than the recommended guidelines [17], whereas Cherniack et al. [26] and Bigelow et al. [27] proposed that oxygen flows for LTOT can be set at $2 \mathrm{~L} /$ minute by nasal cannulae. Unfortunately, we did not investigate this in our study.

We found that the main medical specialists who recommended LTOT to patients were pulmonologists in $57.8 \%$, internists in $20.3 \%$, and other specialists in $12.0 \%$ of the patients. However, the proportion of patients who were appropriately prescribed according to LTOT guidelines was $63.1 \%$. Pulmonologists often presented better adherence to the guidelines (59.2\%) compared to other specialists. Similar data were reported by Verduri et al. [28] who reported that LTOT was prescribed by a pulmonologist in $64.5 \%$, by an internist in $29.3 \%$, and by other specialists in $6.2 \%$ of the patients. While this study appeared to show that the specialty of the prescriber had no impact on the appropriateness of the prescription, we considered that pulmonologists have a greater opportunity to give patients more detailed explanations to improve their understanding and compliance to treatment, making educating physicians, patients, and relatives regarding the use of LTOT crucial.

While there is a broad agreement based on resting $\mathrm{PaO}_{2}$ as to who should receive LTOT, we observed that a significant proportion of patients received LTOT prescription for hypoxemia without meeting the criteria of LTOT guidelines. A significant number of patients (36.8\%) had mean $\mathrm{PaO}_{2}$ higher than $8 \mathrm{kPa}(9.5 \pm 2.67 \mathrm{kPa})$ at the last visit. Our study, that evaluated the medical criteria for LTOT use previously established by LTOT guidelines showed that $36.8 \%$ of patients did not meet the proposed criteria for medical prescription of LTOT. These findings are a cause of concern because they do not correspond to evidence-based recommendations for good clinical practice.

The lack of observance of LTOT criteria appears to be a frequent practice in several studies concerning LTOT. Thus, several series in different countries have reported a significant percentage of patients with LTOT who are incorrectly prescribed LTOT. Studies documenting patients with erroneous prescriptions of LTOT have been reported by Morrison et al. [29] in Scotland (86\%), Munilla et al. [30] in Spain (28.5-46\%), Granados et al. [31] in Spain (42\%), and Guyatt et al. [32] in Canada (40.5\%). A French study showed that $18 \%$ of 7,700 patients who were on LTOT had $\mathrm{PaO}_{2}$ of $>8.0 \mathrm{kPa}$ [33]. In later studies, Chaney et al. [19] observed that $50.5 \%$ of patients with LTOT did not require it in the first evaluation, and in the second evaluation, $58 \%$ of them no longer met the criteria for LTOT. Magnet et al. [34] in Germany found that using a limit value for LTOT at $55 \mathrm{mmHg}$ or $60 \mathrm{mmHg}, 21 \%$ or $30 \%$ of patients, respectively, were overprescribed with LTOT. Additionally, in the study by Rico-Méndez et al. [21], 41.9\% of the population prescribed LTOT was lacking arterial blood gases $\left(\mathrm{PaO}_{2}\right.$ or $\left.\mathrm{SaO}_{2}\right)$, so the prescription of LTOT in patients without COPD was inappropriate. These studies demonstrate an abuse of LTOT prescription worldwide; hence, LTOT should only be administered for strict indications, in accordance with the guidelines, and only in a form suitable for 
individual patients.

It is important to consider that patients with prescription of LTOT often show poor adherence, ranging from $45 \%$ to $70 \%[12,17,24]$. The lack of precise instructions for LTOT prescription limits patient adherence. Adherence is likely to be a central determinant for the effectiveness of LTOT, and more research is needed to evaluate and improve adherence to LTOT. Walshaw et al. [35] concluded that effective prescription and compliance were associated with a respiratory physician more often than a family doctor. Furthermore, regarding erroneous oxygen prescriptions, oxygen costs (nearly 50 dls per 10,000 L in Mexico) are increasing due to the inappropriate use of oxygen [36].

Our survey results, like others, showed that LTOT is frequently prescribed without following the LTOT guidelines, regardless of the medical specialty. Patients need to be able to meet the criteria for LTOT, and they must be clinically stable and should be receiving optimal pharmacological treatment prior to commencement. LTOT is frequently prescribed in an unstable clinical situation or after a single assessment, as reported by several authors [37]. Howard et al. [38] reported that physicians varied widely in their prescribing habits. Approximately 36\% of LTOT patients were prescribed less than 15 hours/day, thus reducing the optimal dosage. Another study found that $55 \%$ of patients had not received thorough written instructions regarding the use of LTOT by their physician, and 63\% were not aware of the importance of LTOT in the therapeutic management of their disease [18]. However, two randomized clinical trials have shown that even if LTOT is appropriately prescribed, it is not as effective as expected.

The Long-Term Oxygen Treatment Trial, a large randomized clinical trial of long-term supplemental oxygen versus no long-term supplemental oxygen in patients with COPD, demonstrated no benefit with respect to survival or first hospitalization during one to six years of follow-up [39]. Lacasse et al., in a double-blind, placebo-controlled, randomized trial, showed no difference in patients with stable COPD regarding survival, rates of exacerbation, hospitalization, and quality of life with nocturnal oxygen therapy in three to four years of follow-up [40].

\section{Limitations}

The limited sample of interviewed patients makes the results difficult to generalize to all local, regional, or national prescriptions. Another limitation was the lack of information concerning the measurement of blood saturation at night and during exercise. Other limitations include adherence to the time of use, used/prescribed oxygen flow, and the fact that during the follow-up the clinical condition of the patient could have changed, which may explain, at least in part, the lack of adherence to the LTOT criteria. Nonetheless, the study provides important preliminary information to design and perform more accurate and larger studies to improve the appropriate observance of LTOT guidance in clinical practice.

\section{Conclusions}

According to our results, we can conclude that there is a significant percentage of patients who do not use LTOT correctly. Moreover, we found that the medical indication of LTOT by physicians is not always correct as they do not base their decision regarding prescribing oxygen on international criteria, which occurs in different regions of the world. The most important finding was that when LTOT is prescribed without any medical criteria, there is a clear non-necessity of LTOT in several patients. This study highlights the importance of establishing healthcare plans that encourage the proper management of LTOT.

\section{Additional Information \\ Disclosures}

Human subjects: Consent was obtained or waived by all participants in this study. Research Ethics Committee of Clinical Medical Unit of Therapy of the IMSS Aguascalientes, Mexico issued approval NA. Animal subjects: All authors have confirmed that this study did not involve animal subjects or tissue. Conflicts of interest: In compliance with the ICMJE uniform disclosure form, all authors declare the following: Payment/services info: All authors have declared that no financial support was received from any organization for the submitted work. Financial relationships: All authors have declared that they have no financial relationships at present or within the previous three years with any organizations that might have an interest in the submitted work. Other relationships: All authors have declared that there are no other relationships or activities that could appear to have influenced the submitted work.

\section{Acknowledgements}

We acknowledge Dr. C Pérez Guzmán for his help in the development of this study.

\section{References}

1. MacIntyre NR: Tissue hypoxia: implications for the respiratory clinician. Respir Care. 2014, 59:1590-6.

10.4187/respcare.03357

2. Branson RD: Oxygen therapy in COPD . Respir Care. 2018, 63:734-48. 10.4187/respcare.06312 
3. Continuous or nocturnal oxygen therapy in hypoxemic chronic obstructive lung disease: a clinical trial. Nocturnal Oxygen Therapy Trial Group. Ann Intern Med. 1980, 93:391-8. 10.7326/0003-4819-93-3-391

4. Long term domiciliary oxygen therapy in chronic hypoxic cor pulmonale complicating chronic bronchitis and emphysema. Report of the Medical Research Council Working Party. Lancet. 1981, 1:681-6.

5. Stoller JK, Panos RJ, Krachman S, Doherty DE, Make B: Oxygen therapy for patients with COPD: current evidence and the long-term oxygen treatment trial. Chest. 2010, 138:179-87. 10.1378/chest.09-2555

6. Rantala HA, Leivo-Korpela S, Lehtimäki L, Lehto JT: Predictors of impaired survival in subjects with longterm oxygen therapy. Respir Care. 2019, 64:1401-9. 10.4187/respcare.06615

7. Wijkstra PJ, Guyatt GH, Ambrosino N, et al.: International approaches to the prescription of long-term oxygen therapy. Eur Respir J. 2001, 18:909-13. 10.1183/09031936.01.00202301

8. Ringbaek TJ: Continuous oxygen therapy for hypoxic pulmonary disease: guidelines, compliance and effects . Treat Respir Med. 2005, 4:397-408. 10.2165/00151829-200504060-00004

9. Standards for the diagnosis and care of patients with chronic obstructive pulmonary disease (COPD) and asthma. This official statement of the American Thoracic Society was adopted by the ATS Board of Directors, November 1986. Am Rev Respir Dis. 1987, 136:225-44. 10.1164/ajrccm/136.1.225

10. Eaton T, Lewis C, Young P, Kennedy Y, Garrett JE, Kolbe J: Long-term oxygen therapy improves healthrelated quality of life. Respir Med. 2004, 98:285-93. 10.1016/j.rmed.2003.10.008

11. Górecka D, Gorzelak K, Sliwiński P, Tobiasz M, Zieliński J: Effect of long-term oxygen therapy on survival in patients with chronic obstructive pulmonary disease with moderate hypoxaemia. Thorax. 1997, 52:674-9. 10.1136/thx.52.8.674

12. Nasiłowski J, Przybyłowski T, Klimiuk J, Leśkow A, Orska K, Chazan R: [Effects of nurse home visits on compliance to long-term oxygen therapy. 14 months follow-up]. Pneumonol Alergol Pol. 2009, 77:363-70.

13. Neri M, Melani AS, Miorelli AM, et al.: Long-term oxygen therapy in chronic respiratory failure: a Multicenter Italian Study on Oxygen Therapy Adherence (MISOTA). Respir Med. 2006, 100:795-806. 10.1016/j.rmed.2005.09.018

14. Mesquita CB, Knaut C, Caram LM, Ferrari R, Bazan SG, Godoy I, Tanni SE: Impact of adherence to long-term oxygen therapy on patients with COPD and exertional hypoxemia followed for one year. J Bras Pneumol. 2018, 44:390-7. 10.1590/S1806-37562017000000019

15. Ringbaek TJ, Viskum K, Lange P: Does long-term oxygen therapy reduce hospitalisation in hypoxaemic chronic obstructive pulmonary disease?. Eur Respir J. 2002, 20:38-42. 10.1183/09031936.02.00284202

16. Ringbaek TJ, Lange P: Trends in long-term oxygen therapy for COPD in Denmark from 2001 to 2010 . Respir Med. 2014, 108:511-6. 10.1016/j.rmed.2013.10.025

17. Ringbaek T, Lange P, Viskum K: Compliance with LTOT and consumption of mobile oxygen . Respir Med. 1999, 93:333-7. 10.1016/s0954-6111(99)90314-1

18. Katsenos S, Froudarakis ME, Charisis A, Vassiliou MP, Constantopoulos SH: Long-term oxygen therapy in Ioannina. Respiration. 2004, 71:619-24. 10.1159/000081763

19. Chaney JC, Jones K, Grathwohl K, Olivier KN: Implementation of an oxygen therapy clinic to manage users of long-term oxygen therapy. Chest. 2002, 122:1661-7. 10.1378/chest.122.5.1661

20. Coleta KD, Silveira LV, Lima DF, Rampinelli EA, Godoy I, Godoy I: Predictors of first-year survival in patients with advanced COPD treated using long-term oxygen therapy. Respir Med. 2008, 102:512-8. 10.1016/j.rmed.2007.12.003

21. Rico Méndez FG, Vázquez BP, Díaz M, Barquera S, Múgica JJ: [Uso y abuso de la prescripción de oxígeno en el domicilio]. Rev Med Inst Mex Seguro Soc. 2003, 41:473-80.

22. Machado MC, Krishnan JA, Buist SA, et al.: Sex differences in survival of oxygen-dependent patients with chronic obstructive pulmonary disease. Am J Respir Crit Care Med. 2006, 174:524-9. 10.1164/rccm.200507$10570 \mathrm{C}$

23. Cooper CB, Waterhouse J, Howard P: Twelve year clinical study of patients with hypoxic cor pulmonale given long term domiciliary oxygen therapy. Thorax. 1987, 42:105-10. 10.1136/thx.42.2.105

24. Atiş S, Tutluoğlu B, Buğdayci R: Characteristics and compliance of patients receiving long-term oxygen therapy (LTOT) in Turkey. Monaldi Arch Chest Dis. 2001, 56:105-9.

25. Gauthier A, Bernard S, Bernard E, Simard S, Maltais F, Lacasse Y: Adherence to long-term oxygen therapy in patients with chronic obstructive pulmonary disease. Chron Respir Dis. 2019, 16:1479972318767724. 10.1177/1479972318767724

26. Cherniack RM, Hakimpour K: The rational use of oxygen in respiratory insufficiency . JAMA. 1967, 199:17882. 10.1001/jama.1967.03120030082015

27. Bigelow DB, Petty TL, Levine BL, Filley GF, Finigan MM: The effect of oxygen breathing on arterial blood gases in patients with chronic airway obstruction living at 5,200 feet. Am Rev Respir Dis. 1967, 96:28-34. 10.1164/arrd.1967.96.1.28

28. Verduri A, Ballerin L, Simoni M, et al.: Poor adherence to guidelines for long-term oxygen therapy (LTOT) in two Italian university hospitals. Intern Emerg Med. 2014, 9:319-24. 10.1007/s11739-012-0898-2

29. Morrison D, Skwarski K, MacNee W: Review of the prescription of domiciliary long term oxygen therapy in Scotland. Thorax. 1995, 50:1103-5. 10.1136/thx.50.10.1103

30. Munilla E, Carrizo S, Hernández A, Vela J, Marín JM: [Continuous domiciliary oxygen therapy in Zaragoza: a cross-sectional home study]. Arch Bronconeumol. 1996, 32:59-63. 10.1016/s0300-2896(15)30811-5

31. Granados A, Escarrabill J, Borràs JM, Rodríguez-Roisín R: The importance of process variables analysis in the assessment of long-term oxygen therapy by concentrator. Respir Med. 1997, 91:89-93. 10.1016/s09546111(97)90073-1

32. Guyatt GH, McKim DA, Austin P, Bryan R, Norgren J, Weaver B, Goldstein RS: Appropriateness of domiciliary oxygen delivery. Chest. 2000, 118:1303-8. 10.1378/chest.118.5.1303

33. Veale D, Chailleux E, Taytard A, Cardinaud JP: Characteristics and survival of patients prescribed long-term oxygen therapy outside prescription guidelines. Eur Respir J. 1998, 12:780-4. 10.1183/09031936.98.12040780

34. Magnet FS, Majorski DS, Callegari J, Schwarz SB, Schmoor C, Windisch W, Storre JH: Capillary PO2 does not adequately reflect arterial PO2 in hypoxemic COPD patients. Int J Chron Obstruct Pulmon Dis. 2017, 12:2647-53. 10.2147/COPD.S140843 


\section{Cureus}

35. Walshaw MJ, Lim R, Evans CC, Hind CR: Factors influencing the compliance of patients using oxygen concentrators for long-term home oxygen therapy. Respir Med. 1990, 84:331-3. 10.1016/s09546111(08)80062-5

36. Turner AM, Sen S, Steeley C, Khan Y, Sweeney P, Richards Y, Mukherjee R: Evaluation of oxygen prescription in relation to hospital admission rate in patients with chronic obstructive pulmonary disease. BMC Pulm Med. 2014, 14:127. 10.1186/1471-2466-14-127

37. Güell Rous R: Long-term oxygen therapy: are we prescribing appropriately?. Int J Chron Obstruct Pulmon Dis. 2008, 3:231-7. 10.2147/copd.s1230

38. Howard P, Waterhouse JC, Billings CG: Compliance with long-term oxygen therapy by concentrator . Eur Respir J. 1992, 5:128-9.

39. Albert RK, Au DH, Blackford AL, et al.: A randomized trial of long-term oxygen for COPD with moderate desaturation. N Engl J Med. 2016, 375:1617-27. 10.1056/NEJMoa1604344

40. Lacasse Y, Sériès F, Corbeil F, et al.: Randomized trial of nocturnal oxygen in chronic obstructive pulmonary disease. N Engl J Med. 2020, 383:1129-38. 10.1056/NEJMoa2013219 